\title{
Thorax: from the new Editorial Office
}

As most readers are probably by now aware, we took over as Executive Editors of Thorax on 1 January 1996. Since then the Editorial Office has moved from London to Nottingham, we have appointed a new Editorial Assistant and some new faces to the Board of Associate Editors, and have dealt with the huge backlog of manuscripts that built up in the process of the move. We are now beginning to see papers coming through for publication in the journal that have been reviewed from start to finish by the new editorial team. Now is perhaps a good time to reflect on the journal and the changes that we would like to see in the next few years.

First, however, we express our thanks to the previous Executive Editor, Stephen Spiro, who initiated so many changes and improvements to Thorax during his period of office. We inherited the journal in excellent form, with a healthy rate of submission of high quality manuscripts, a substantial stock of good papers ready for publication, and with review series and editorials planned many months into the future. Under Stephen's guidance, Thorax has developed its competitiveness in the field of respiratory medicine and established itself as a major international journal. All credit is due to Stephen and his Editorial Assistant, Angela Betchley, for their hard work.

One of the consequences of Stephen's success with the journal was, however, that the work involved in running Thorax increased considerably. It now attracts well over 800 manuscripts a year and publishes a range of supplements and reviews. To deal with this workload, some changes in the editorial process are inevitable. We have therefore taken on Thorax as joint Executive Editors to share this workload but, to ensure a rapid turnover of good papers for publication and quick responses to authors, we have also introduced some changes to the review process. These are as follows:

1. We have introduced an initial screen of papers to select out those that, for any reason, are not suitable or are unlikely to be sufficiently competitive to merit a place in the journal. We feel the papers that we know from the outset are almost certain to be rejected should be returned to the authors immediately so that they have the opportunity to send the paper elsewhere, and so that our referees are not overburdened with manuscripts that are not going to succeed with us. We see this rapid rejection of papers as a positive move and hope that authors agree.
2. Having reduced the number of papers going out to Associate Editors and referees, we are asking these individuals to return papers quickly to provide a faster response to authors. We aim to get our publication times down to a minimum for all papers, but in recognising that certain papers do deserve or need particularly rapid publication we have introduced a Rapid Communications facility whereby papers submitted in a particular abbreviated format are reviewed in an accelerated process. We hope that we will be able to attract novel scientific or important and timely clinical papers to this section of the journal.

3. Having thus streamlined the review process to achieve rapid responses, we ask submitting authors to play their part by submitting papers in a format that is relatively easy to review. Pressure on page space in Thorax is intense, so we ask that all papers are concise, that they follow the guidelines laid down in the instructions to authors and that, where possible, papers that have a short simple message are submitted as short reports.

One final development is that, because of the increasing complexity and importance of statistical analysis in scientific papers, we have appointed a statistician to the Associate Editorial Board. The Statistical Editor will now screen the majority of manuscripts accepted for publication, usually at the stage of return to the authors for revision with a view to publication, and recommend any statistical changes that are necessary. We are already aware that this additional step in the review process has contributed to a rise in the standard of papers being accepted for the journal.

Overall our view for Thorax is to ensure that it continues to compete as an international respiratory journal, continues to attract high quality manuscripts from around the world, and provides good service to its authors by responding with considered and informed comments and criticisms in reasonable time. Already we are aware that editing Thorax involves a substantial workload, but that the workload is immensely challenging and often very enjoyable. We relish the prospect of editing Thorax for the next few years and hope that the enthusiasm of all involved in the journal will be reflected in the standard of Thorax in the future.

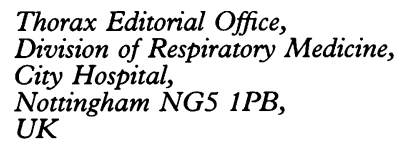
UK

JOHN BRITTON ALAN J KNOX Executive Editors

Readers may be interested to know that Thorax contents lists, subscription information and instructions for authors are now shown on the BMJ page on the World Wide Web at http://www.bmj.com/bmj/. 